\title{
Examining the association between adiposity and biochemical recurrence after radical prostatectomy
}

Ross J. Mason, MD ${ }^{1}$; Stephen A. Boorjian, $\mathrm{MD}^{1}$; Bimal Bhindi, $\mathrm{MD}^{1}$; Laureano Rangel; $\mathrm{MS}^{2}$; Igor Frank, MD ${ }^{1}$; R. Jeffrey Karnes, MD ${ }^{1}$; Matthew K. Tollefson, MD ${ }^{1}$

${ }^{1}$ Department of Urology; ${ }^{2}$ Department of Health Science Research; Mayo Clinic, Rochester, MN, United States

Acknowledgements: This study was made possible by the CTSA Grant UL1 TR000135 from the National Center for Advancing Translational Sciences (NCATS), a component of the National Institutes of Health (NIH). Its contents are solely the responsibility of the authors and do not necessarily represent the official views of the National Institutes of Health.

Cite as: Can Urol Assoc J 2018 March 19; Epub ahead of print. http://dx.doi.org/10.5489/cuaj.4923

Published online March 19, 2018

\section{$* * *$}

\section{Abstract:}

Introduction: Herein we examined the association between adiposity, as measured with computed tomography (CT), and biochemical recurrence (BCR) after RP.

Methods: Using axial CT images, preoperative fat mass index (FMI) was calculated for 698 men who underwent RP from 2007-2010 by using measurements of total surface area of adipose tissue at the L3 level. Obesity was classified according to NHANES standards for obesity (FMI $>9 \mathrm{~kg} / \mathrm{m}^{2}$ ). The associations between obesity and the distribution of adiposity (visceral vs. subcutaneous) with BCR were examined using the Kaplan-Meier method and Cox proportional hazards regression analyses.

Results: Obese men were older than non-obese men (63.0 vs. 60.7 years; $p<0.001$ ), but were similar with regards to all other clinical and pathological characteristics. With a median followup of six years, 152 patients were diagnosed with BCR. Five-year BCR-free survival was similar between obese and non-obese patients (80.6\% vs. 82.1\%; p=0.27). Furthermore, in multivariable analyses, obesity was not independently associated with the risk of BCR (hazard ratio [HR] 1.02; 95\% confidence interval [CI] 0.73-1.43). Similar results were obtained when analyzing FMI as a continuous variable (HR 1.02; 95\% CI 0.94-1.09 for each $1 \mathrm{~kg} / \mathrm{m}^{2}$ increase in FMI). Additionally, not visceral adiposity, subcutaneous adiposity, or visceral-to-subcutaneous adiposity ratio were associated with BCR (all p>0.05) in multivariable analyses. 
Conclusions: Neither total abdominal adiposity nor the distribution of adiposity were independently associated with BCR after RP in this study. As such, the presence of obesity may not be a marker of increased oncological risk after RP.

\section{Introduction}

The association between obesity and malignancy is a major public health concern with obesity being recognized as a significant risk factor for the development of several human cancers ${ }^{(1,2)}$. However, obesity appears to have a variable effect on oncologic aggressiveness and survival ${ }^{(3)}$. Specific to prostate cancer, obesity is associated with an increased incidence of clinically significant prostate cancer ${ }^{(2,4,5)}$ but there are conflicting reports on whether obesity is independently associated with biochemical recurrence (BCR) and cancer-specific outcomes among men treated for localized prostate cancer ${ }^{(6-14)}$.

Currently available studies investigating the association between body composition and prostate cancer outcomes are limited by the abundant use of body mass index (BMI). BMI is a crude measure of obesity that does not account for differences in body composition and is not linearly associated with adiposity ${ }^{(15,16)}$. Indeed, more accurate measures of body composition are available with cross sectional imaging being considered the gold standard ${ }^{(17,18)}$. Cross-sectional imaging can accurately quantify adiposity and also allows for the measurement of fat distribution.

Recognizing the conflicting results and limitations of currently available studies, we examined the association between both total abdominal adiposity and the distribution of adiposity (visceral and subcutaneous adipose tissue), as measured using axial computed tomography (CT), and BCR in men undergoing RP for localized prostate cancer.

\section{Methods}

Patient selection and data collection

After Institutional Review Board Approval, we identified all men who underwent open or robot assisted radical prostatectomy between 2007 and 2010 at a single institution and had an available CT scan of the abdomen performed within the 6 months preceding surgery. Patients were excluded if they had previously received prostate radiation or androgen deprivation or if they had metastatic disease at the time of RP. In addition, men were excluded if their pre-operative CT scan was of insufficient quality for body composition analysis.

Clinical and pathological data were collected from our institutionally maintained radical prostatectomy registry. Clinical data included age, height, weight, clinical T and $\mathrm{N}$ stage, preoperative PSA, receipt of adjuvant radiation, and receipt of adjuvant androgen deprivation therapy. Pathological data included pathological T and N stage, biopsy and prostatectomy Gleason grade, and surgical margin status.

The primary outcome of interest was BCR after RP, defined as a post-operative PSA > $0.4 \mathrm{ng} / \mathrm{ml}^{(19)}$. Secondary outcomes of interest included systemic progression (SP) and all-cause 
mortality after RP. SP was defined as any demonstrable metastasis on post-operative imaging or on biopsies outside of the surgical bed. Follow-up was not standardized after surgery, but in general, patients undergo PSA testing every 3 to 4 months for the first two years after RP, every 6 months for three additional years, and then annually. For patients followed outside of our institution, outcomes are collected annually by registry data abstractors using patient and physician correspondence. Vital status is obtained from either death certificates or physician correspondence.

\section{Body composition analysis}

Using a representative axial CT image from the L3 level, the cross sectional area of visceral, intramuscular, and subcutaneous adipose tissue was measured for each patient using attenuation thresholds specific to these areas (Hounsfield units $=-190$ to -30 for subcutaneous and intramuscular adipose tissue and -150 to -30 for subcutaneous adipose tissue) (Figure 1). Following this, the total fat mass was calculated for each patient using the equation proposed by Mourtzakis et al which was developed to convert measurements of cross sectional adipose area at the L3 level to fat mass (FM) ${ }^{(20)}$. The fat mass index (FMI) was then calculated for each patient by dividing FM by height squared $\left(\mathrm{m}^{2}\right)$. In addition, the visceral adiposity index (VAI) and subcutaneous adiposity index (SAI) were calculated by dividing the surface area of these tissues at the L3 level by height squared.

All body composition analyses were performed by a single investigator (RJM) using Slice-O-Matic software (version 5.0, Tomovision, Quebec, Canada).

\section{Statistical analysis}

The association between adiposity measures and BCR-free survival, SP-free survival, and overall survival (OS) were investigated using the Kaplan-Meier method and Cox-Proportion Hazards regression. FMI was analyzed as a continuous and as a binary variable with patients being classified as obese or non-obese according to the National Health and Nutrition Examination Survey (NHANES) standards for obesity $\left(\text { FMI }>9 \mathrm{~kg} / \mathrm{m}^{2}\right)^{(21)}$. In addition, the potential impact of the distribution of adiposity was examined by evaluating the association between VAI and SAI as well as the ratio of visceral adiposity to subcutaneous adiposity and BCR (analyzed as continuous variables). Clinical and pathological variables significant at the alpha $=0.05$ level in univariable analysis were included in the multivariable models along with the adiposity measure of interest.

Pre-planned subgroup analyses were performed according to National Comprehensive Cancer Network (NCCN) risk categories (very low/low, intermediate, high/very high) ${ }^{(22)}$. In addition, one-way sensitivity analyses were performed to determine whether class of obesity was associated with BCR and to determine the effect of varying the binary FMI cutoff. Statistical analyses were performed using SAS version 9.4 (SAS Institute, Cary, NC) and R version 3.3.2 (R Foundation for Statistical Computing, Vienna, Austria). All tests were two-sided, with pvalues $<0.05$ considered statistically significant. 


\section{Results}

We identified 698 patients who underwent RP between 2007-2010 and who had a pre-operative CT scan available for analysis. Body composition characteristics for the entire cohort are shown in Table 1. Overall, 344 (49.3\%) patients were classified as obese according to their FMI.

Clinical characteristics according to adiposity classification are shown in Table 2. Obese patients were older than non-obese patients (mean age 63.0 years versus 60.7 years, $\mathrm{p}<0.001$ ) but otherwise had similar preoperative PSA, clinical Gleason grade, and clinical $\mathrm{T}$ and $\mathrm{N}$ stage. Similarly, there were no significant differences in pT stage, nodal status, pathological Gleason grade, or positive surgical margin rate between obese and non-obese patients. Additionally, there was no significant difference in the receipt of adjuvant radiation among obese and non-obese patients.

With a median follow-up after RP of 6.0 years (IQR 5.0 - 7.0), a total of 152 patients were diagnosed with BCR. In addition, 57 patients were diagnosed with SP and 50 patients died during follow-up. Among the patients who died from any cause, there were 16 (32\%) who had previously experienced BCR. On Kaplan-Meier analysis, there was no significant difference in the five-year BCR free survival between obese and non-obese patients (80.6\% versus 82.1\%; $\mathrm{p}=0.27$ ) (Figure 2). Furthermore, on multivariable Cox analysis, obesity was not independently associated with the risk of BCR (HR 1.02; 95\% CI 0.73-1.43) (Table 3). The results remained unchanged when FMI was analyzed as a continuous variable (HR 1.02; 95\% CI 0.94 - 1.09 for each $1 \mathrm{~kg} / \mathrm{m}^{2}$ increase in FMI).

Similarly, neither increasing visceral adiposity index (HR 1.00; 95\% CI 0.99 -1.01 for each $1 \mathrm{~cm}^{2} / \mathrm{m}^{2}$ ) nor subcutaneous adiposity index (HR 1.00; 95\% CI 0.99 - 1.01 for each $1 \mathrm{~cm}^{2} / \mathrm{m}^{2}$ ) were found to be associated with BCR. Finally, the ratio of visceral to subcutaneous adiposity was likewise not significantly associated with BCR after RP (HR 1.01; 95\% CI 0.99 1.03 for each 0.1 increase in ratio).

\section{Subgroup and sensitivity analyses}

In a subgroup analysis according to National Comprehensive Cancer Network (NCCN) risk categories, obesity was not significantly associated with BCR in any of the risk categories on multivariable analyses (all p > 0.05). The results of this subgroup analysis are shown in Table 4 .

In sensitivity analysis, we found that patients with class 2 obesity (FMI $>12-15 \mathrm{~kg} / \mathrm{m}^{2}$ ) or class 3 obesity (FMI $>15 \mathrm{~kg} / \mathrm{m}^{2}$ ) were not at an increased risk of BCR compared with non-obese patients (both $\mathrm{p}>0.05$ ). In addition, using different binary FMI cutoffs ( $\leq$ or $>6,12$, and 15 $\mathrm{kg} / \mathrm{m}^{2}$ ) did not significantly alter the results (all $\mathrm{p}>0.05$ ). The results of these sensitivity analyses are shown in Table 5.

Secondary endpoints

On Kaplan-Meier analysis, obesity was not significantly associated with either SP free survival or OS ( $\mathrm{p}=0.64$ and 0.43 , respectively). In addition, in multivariable Cox analysis, obesity was 
not significantly associated with SP or OS (Supplemental Table 1). Again, these results remained unchanged when analyzing FMI as a continuous variable.

\section{Discussion}

Herein, we examined the association between adiposity, as measured using axial CT, and oncologic outcomes in men undergoing RP. We found that neither total abdominal adiposity nor the distribution of adiposity were independently associated with biochemical recurrence after RP. Importantly, these results remained unchanged in subgroup analyses according to prostate cancer risk categories. Furthermore, the severity of obesity was not predictive of BCR after RP. Additionally, in a secondary exploratory analysis we found no significant association between adiposity and either SP or OS after RP. We conclude that obesity itself is not an independent risk factor for adverse oncologic outcomes among men undergoing RP after accounting for other well-known prognostic factors.

The complex relationship between obesity and prostate cancer remains controversial. At the population level, obesity appears to be associated with an increased incidence of advanced prostate cancer $^{(2,4,5)}$. In addition, several observational studies have identified that obese men undergoing treatment for localized prostate cancer have higher Gleason scores, pathologic stage, and positive margin rates compared with non-obese $\operatorname{men}^{(9,10,13)}$. Nonetheless, although obesity appears to be associated with more advanced disease at diagnosis, previous studies investigating whether obesity confers a higher risk of adverse oncologic outcomes among men with similar disease characteristics have had conflicting results ${ }^{(6-14)}$. In a meta-analysis by Hu et al examining the association between obesity and biochemical recurrence in men with localized prostate cancer, a small increased risk of BCR was noted after RP (HR 1.17; 95\% CI $1.07-1.28)^{(14)}$. However, among the 18 studies included, there was significant heterogeneity in the outcomes with 8 of the included studies reporting an association between obesity and BCR and 10 studies reporting no association. Overall, whether an association between obesity and oncologic outcomes after RP exists remains uncertain.

The majority of currently available studies examining obesity and outcomes after RP are limited by the use of BMI as the measure of obesity, which is unable to adequately characterize body composition. Specifically, BMI does not separate skeletal muscle from adiposity and does not measure the distribution of adiposity ${ }^{(15,16)}$. Multiple more accurate methods are available for measuring body composition including waist to hip circumference ratio, dual energy X-ray absorptiometry, and bioelectrical impedance analysis. However, cross-sectional imaging with CT or MRI is largely considered the gold standard ${ }^{(17,18)}$. Furthermore, cross sectional imaging is often performed as part of routine staging for cancer patients, allowing for body composition analysis to be performed without the need for additional testing. To our knowledge, only one previous study has utilized CT to investigate the association between adiposity and outcomes after radical prostatectomy ${ }^{(23)}$. In a study including 283 men undergoing RP, Ohwaki et al found no association between visceral adiposity and $\mathrm{BCR}^{(23)}$. However, their study had a small number of patients with biochemical recurrence $(n=41)$, had a short median follow-up (2.5 years), and 
did not investigate the potential association between total body adiposity and BCR ${ }^{(23)}$. Thus, the current study represents the most comprehensive assessment to date on the association between adiposity and biochemical recurrence after radical prostatectomy.

Several mechanisms have been proposed to explain the potential link between obesity and prostate cancer oncogenesis including the effects of decreased circulating androgen levels ${ }^{(24,}$ ${ }^{25)}$, chronic inflammation ${ }^{(26)}$, and alterations in the insulin/insulin like growth factor (IGF-1) axes ${ }^{(27-29)}$. Interestingly, visceral adipose tissue is more metabolically active than subcutaneous adipose tissue and visceral obesity is associated with greater alterations in all of these proposed pathways $^{(30)}$. Thus, we hypothesized that the distribution of adiposity may be associated with the risk of BCR after RP. However, we again found no association between increasing visceral adiposity or the ratio of visceral to subcutaneous adiposity and BCR, strengthening our conclusion that adiposity is not independently associated with oncologic control after RP.

Several limitations to the current study warrant mention here. The retrospective nature of this study makes it subject to the selection biases inherent in this type of research. Additionally, the median follow-up is intermediate at 5.9 years, limiting the ability to conclude definitively whether SP or OS are impacted by adiposity. Finally, this study only measured adiposity at a single point in time and thus does not account for potential changes that could occur throughout follow-up. These limitations notwithstanding, we feel our results provide evidence that obesity may not play an independent role in biochemical recurrence among men undergoing RP.

\section{Conclusions}

Neither total abdominal adiposity nor the distribution of adiposity was independently associated with biochemical recurrence after RP in this study. After accounting for other known prognostic factors, the presence of obesity may not be associated with worse oncologic outcomes after 


\section{References}

1. Bhaskaran K, Douglas I, Forbes H et al. Body-mass index and risk of 22 specific cancers: a population-based cohort study of 5.24 million UK adults. Lancet 2014;384: 755-65.

2. Renehan AG, Tyson M, Egger $M$ et al. Body-mass index and incidence of cancer: a systematic review and meta-analysis of prospective observational studies. Lancet 2008;371: 569-78.

3. Greenlee H, Unger JM, LeBlanc M et al. Association between Body Mass Index and Cancer Survival in a Pooled Analysis of 22 Clinical Trials. Cancer Epidemiol Biomarkers Prev 2017;26: 21-9.

4. Bergstrom A, Pisani P, Tenet V et al. Overweight as an avoidable cause of cancer in Europe. Int J Cancer 2001; 91: 421-30.

5. MacInnis RJ, English DR. Body size and composition and prostate cancer risk: systematic review and meta-regression analysis. Cancer Causes Control 2006;17: 9891003.

6. Asmar R, Beebe-Dimmer JL, Korgavkar K et al. Hypertension, obesity and prostate cancer biochemical recurrence after radical prostatectomy. Prostate cancer Prostatic Dis 2013; 16: 62-6.

7. Ho T, Gerber L, Aronson WJ et al. Obesity, prostate-specific antigen nadir, and biochemical recurrence after radical prostatectomy: biology or technique? Results from the SEARCH database. Eur Urol 2012;62: 910-6.

8. Tomaszewski JJ, Chen YF, Bertolet $\mathrm{M}$ et al. Obesity is not associated with aggressive pathologic features or biochemical recurrence after radical prostatectomy. Urology 2013;81:992-6.

9. Freedland SJ, Aronson WJ, Kane CJ et al. Impact of obesity on biochemical control after radical prostatectomy for clinically localized prostate cancer: a report by the Shared Equal Access Regional Cancer Hospital database study group. J Clin Oncol 2004;22:44653.

10. Siddiqui SA, Inman BA, Sengupta $S$ et al. Obesity and survival after radical prostatectomy: A 10-year prospective cohort study. Cancer 2006;107:521-9.

11. Mucksavage P, Mitchell C, Kutikov A et al. Anthropometric differences in obese men with biochemical failure after radical retropubic prostatectomy. Urol Oncol 2012;30:5905.

12. Freedland SJ, Sun L, Kane CJ et al. Obesity and oncological outcome after radical prostatectomy: impact of prostate-specific antigen-based prostate cancer screening: results from the Shared Equal Access Regional Cancer Hospital and Duke Prostate Center databases. BJU Int 2008;102:969-74. 
13. Magheli A, Rais-Bahrami S, Trock BJ et al. Impact of body mass index on biochemical recurrence rates after radical prostatectomy: an analysis utilizing propensity score matching. Urology 2008;72:1246-51.

14. Hu MB, Xu H, Bai PD et al. Obesity has multifaceted impact on biochemical recurrence of prostate cancer: a dose-response meta-analysis of 36,927 patients. Med Oncol 2014;31:829.

15. Rothman KJ. BMI-related errors in the measurement of obesity. Int J Obese 2008;32 Suppl 3:S56-9.

16. Prentice AM, Jebb SA. Beyond body mass index. Obesity rev 2001;2:141-7.

17. Yip C, Dinkel C, Mahajan A, Siddique M, Cook GJ, Goh V. Imaging body composition in cancer patients: visceral obesity, sarcopenia and sarcopenic obesity may impact on clinical outcome. Insights Imaging 2015;6:489-97.

18. Shuster A, Patlas M, Pinthus JH, Mourtzakis M. The clinical importance of visceral adiposity: a critical review of methods for visceral adipose tissue analysis. $\mathrm{Br} \mathrm{J}$ Radiol 2012;85:1-10.

19. Amling CL, Bergstralh EJ, Blute ML, Slezak JM, Zincke H. Defining prostate specific antigen progression after radical prostatectomy: what is the most appropriate cut point? $J$ Urol 2001;165:1146-51.

20. Mourtzakis M, Prado CM, Lieffers JR, Reiman T, McCargar LJ, Baracos VE. A practical and precise approach to quantification of body composition in cancer patients using computed tomography images acquired during routine care. Appl Physiol Nutr Metab 2008;33:997-1006.

21. Kelly TL, Wilson KE, Heymsfield SB. Dual energy X-Ray absorptiometry body composition reference values from NHANES. PloS one 2009;4:e7038.

22. National Comprehensive Cancer Network Guidelines. Prostate Cancer Guidelines. 2017 (Version 2). Available at https://www.nccn.org/professionals/physician_gls/PDF/prostate.pdf. Accessed August $19^{\text {th }}, 2017$

23. Ohwaki K, Endo F, Hattori K. Abdominal obesity, hypertension, antihypertensive medication use and biochemical recurrence of prostate cancer after radical prostatectomy. Eur J Cancer 2015;51:604-9.

24. Mah PM, Wittert GA. Obesity and testicular function. Mol Cell Endocrinol 2010;316: 180-6.

25. Schnoeller T, Jentzmik F, Rinnab L et al. Circulating free testosterone is an independent predictor of advanced disease in patients with clinically localized prostate cancer. World J Urol 2013;31:253-9.

26. Grivennikov SI, Greten FR, Karin M. Immunity, inflammation, and cancer. Cell 2010;140:883-99. 
27. Lewitt MS, Dent MS, Hall K. The Insulin-Like Growth Factor System in Obesity, Insulin Resistance and Type 2 Diabetes Mellitus. J Clin Med 2014; 3: 1561-74.

28. Louie SM, Roberts LS, Nomura DK. Mechanisms linking obesity and cancer. Biochim Biophys Acta 2013;1831:1499-508.

29. Venkateswaran V, Haddad AQ, Fleshner NE et al. Association of diet-induced hyperinsulinemia with accelerated growth of prostate cancer (LNCaP) xenografts. $J$ Natl Canc Inst 2007;99:1793-800.

30. Ibrahim MM. Subcutaneous and visceral adipose tissue: structural and functional differences. Obes Rev 2010;11:11-8. 


\section{Figures and Tables}

Fig. 1. Axial computed tomography (CT) showing a patient with (A) and without (B) obesity. The yellow, teal and green areas represent visceral, subcutaneous, and intramuscular adipose tissue, respectively, and the red represents skeletal muscle.

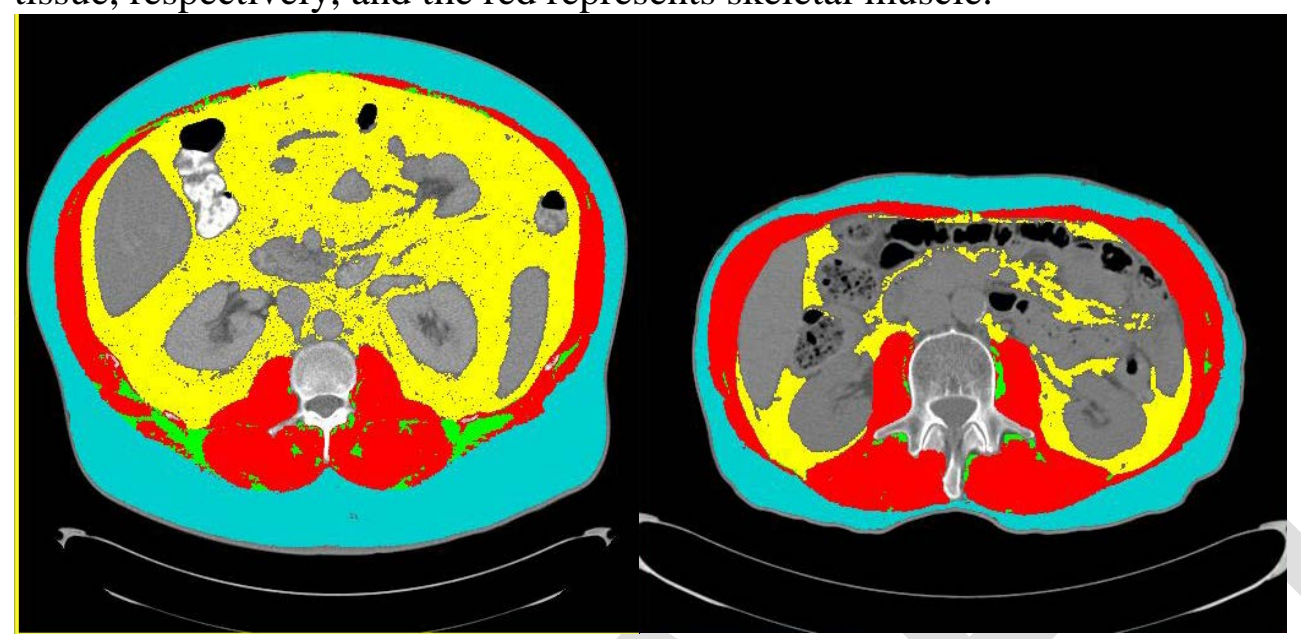

Fig. 2. Kaplan-Meier analysis depicting biochemical recurrence (BCR)-free survival for obese and non-obese men.

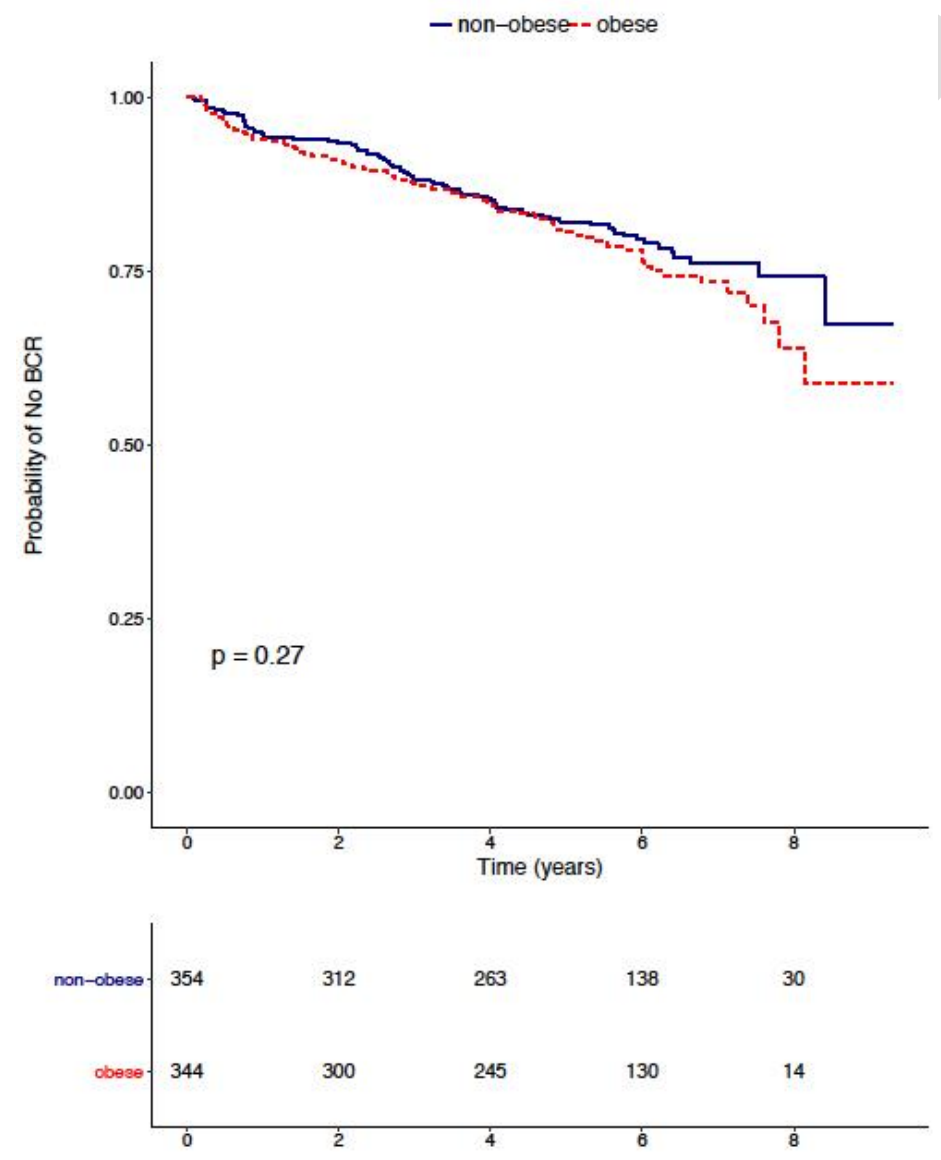




\begin{tabular}{|l|l|}
\hline \multicolumn{2}{|l|}{ Table 1. Preoperative body composition characteristics } \\
\hline $\mathrm{N}$ & 698 \\
\hline Mean FMI & $9.1(\mathrm{SD} 2.2)$ \\
\hline Non-obese $\left(\mathrm{FMI} \leq 9 \mathrm{~kg} / \mathrm{m}^{2}\right)$ & $354(50.7 \%)$ \\
\hline Obese $\left(\mathrm{FMI}>9 \mathrm{~kg} / \mathrm{m}^{2}\right)$ & $344(49.3 \%)$ \\
\hline Class 1 obesity $\left(\mathrm{FMI}>9-12 \mathrm{~kg} / \mathrm{m}^{2}\right)$ & $273(39.1 \%)$ \\
\hline Class 2 obesity $\left(\mathrm{FMI}>12-15 \mathrm{~kg} / \mathrm{m}^{2}\right)$ & $63(9.0 \%)$ \\
\hline Class 3 obesity $\left(\mathrm{FMI}>15 \mathrm{~kg} / \mathrm{m}^{2}\right)$ & $8(1.1 \%)$ \\
\hline
\end{tabular}

FMI: fat mass index; SD: standard deviation;

\section{Table 2. Clinical characteristics according to obesity classification}

\begin{tabular}{|l|c|c|c|c|}
\hline & Overall & $\begin{array}{c}\text { Non-obese } \\
\text { (FMI } \leq \mathbf{9} \\
\left.\mathbf{k g} / \mathbf{m}^{2}\right)\end{array}$ & $\begin{array}{c}\text { Obese (FMI } \\
\left.\mathbf{9} \mathbf{~ k g} / \mathbf{m}^{2}\right)\end{array}$ & p \\
\hline $\mathrm{N}$ & 698 & $355(50.8 \%)$ & $344(49.2 \%)$ & \\
\hline Mean age at surgery (years) & $61.8(\mathrm{SD} 7.1)$ & $60.7(\mathrm{SD} 7.3)$ & $63.0(\mathrm{SD} 6.8)$ & $<0.001$ \\
\hline cT stage & & & & 0.49 \\
\hline 1 & $402(57.6 \%)$ & $194(54.8 \%)$ & $208(60.5 \%)$ & \\
\hline 2 & $261(37.4 \%)$ & $138(39.0 \%)$ & $123(35.8 \%)$ & \\
\hline $3-4$ & $21(3.0 \%)$ & $10(2.8 \%)$ & $11(3.2 \%)$ & \\
\hline Unknown & $14(2.0 \%)$ & $12(3.4 \%)$ & $2(0.6 \%)$ & \\
\hline cN stage & & & & 0.97 \\
\hline $0-\mathrm{x}$ & $690(99.0 \%)$ & $351(99.2 \%)$ & $340(98.8 \%)$ & \\
\hline 1 & $7(1.0 \%)$ & $3(0.8 \%)$ & $4(1.2 \%)$ & \\
\hline Mean preoperative PSA (ng/ml) & $8.7(9.3 \%)$ & $8.2(8.3 \%)$ & $9.3(10.2 \%)$ & 0.1 \\
\hline Clinical Gleason grade & & & & 0.21 \\
\hline 6 & $276(39.5 \%)$ & $145(41.0 \%)$ & $131(38.1 \%)$ & \\
\hline 7 & $274(39.3 \%)$ & $144(40.7 \%)$ & $130(37.8 \%)$ & \\
\hline 8-10 & $136(19.5 \%)$ & $60(16.9 \%)$ & $76(22.1 \%)$ & \\
\hline Unknown & $12(1.7 \%)$ & $5(1.4 \%)$ & $7(2.0 \%)$ & \\
\hline pT stage & & & & 0.99 \\
\hline 2 & $496(71.1 \%)$ & $251(70.9 \%)$ & $245(71.2 \%)$ & \\
\hline $3-4$ & $202(28.9 \%)$ & $103(29.1 \%)$ & $99(28.8 \%)$ & \\
\hline pN stage & $659(94.4 \%)$ & $333(94.1 \%)$ & $326(94.8 \%)$ & \\
\hline $0-x$ & & & & \\
\hline
\end{tabular}




\begin{tabular}{|l|c|c|c|c|}
\hline 1 & $39(5.6 \%)$ & $21(5.9 \%)$ & $18(5.2 \%)$ & \\
\hline Pathologic Gleason grade & & & & 0.13 \\
\hline 6 & $194(27.8 \%)$ & $108(30.5 \%)$ & $86(25.0 \%)$ & \\
\hline 7 & $384(55.0 \%)$ & $193(54.5 \%)$ & $191(55.5 \%)$ & \\
\hline $8-10$ & $118(16.9 \%)$ & $52(14.7 \%)$ & $66(19.2 \%)$ & \\
\hline Unknown & $2(0.3 \%)$ & $1(0.3 \%)$ & $1(0.3 \%)$ & \\
\hline Surgical margin status & & & & 0.09 \\
\hline Negative & $532(76.2 \%)$ & $280(79.1 \%)$ & $252(73.3 \%)$ & \\
\hline Positive & $166(23.8 \%)$ & $74(20.9 \%)$ & $92(26.7 \%)$ & \\
\hline Receipt of adjuvant radiation & $23(3.0 \%)$ & $10(2.8 \%)$ & $13(3.8 \%)$ & 0.65 \\
\hline Receipt of adjuvant ADT & $63(9.0 \%)$ & $34(9.6 \%)$ & $29(8.4 \%)$ & 0.37 \\
\hline
\end{tabular}

ADT: androgen-deprivation therapy; PSA: prostate-specific antigen; SD: standard deviation.

\begin{tabular}{|c|c|c|}
\hline & Multivariable HR (95\% CI) & $\mathbf{p}$ \\
\hline & Obesity & \\
\hline Obesity ( $>$ vs $\leq 9 \mathrm{~kg} / \mathrm{m}^{2}$ ) & $1.02(0.73-1.43)$ & 0.90 \\
\hline Age & $1.00(0.98-1.03)$ & 0.68 \\
\hline \multicolumn{3}{|l|}{ Pathologic Gleason grade (ref $=7$ ) } \\
\hline 6 & $0.09(0.03-0.28)$ & $<0.001$ \\
\hline $8-10$ & $1.98(1.39-2.84)$ & $<0.001$ \\
\hline \multicolumn{3}{|l|}{ pT stage $($ ref $=$ pT2) } \\
\hline $\mathrm{pT} 3 / 4$ & $1.87(1.29-2.70)$ & $<0.001$ \\
\hline pN1 disease $($ ref = N0/x) & $0.74(0.38-1.42)$ & 0.36 \\
\hline Pre-operative PSA* & $1.18(1.01-1.38)$ & 0.04 \\
\hline Positive margins & $1.49(1.05-2.11)$ & 0.03 \\
\hline \multirow[t]{2}{*}{ Adjuvant ADT } & $0.89(0.52-1.49)$ & 0.65 \\
\hline & Visceral adiposity & \\
\hline \multirow[t]{2}{*}{$\mathrm{VAI}^{* *}$ (for each $1 \mathrm{~cm}^{2} / \mathrm{m}^{2}$ increase) } & $1.00(0.99-1.01)$ & 0.35 \\
\hline & Subcutaneous adiposity & \\
\hline \multirow[t]{2}{*}{$\mathrm{SAI}^{* *}$ (for each $1 \mathrm{~cm}^{2} / \mathrm{m}^{2}$ increase) } & $1.00(0.99-1.01)$ & 0.95 \\
\hline & Visceral to subcutaneous ratio & \\
\hline $\mathrm{VAI} / \mathrm{SAI} * *$ & $1.01(0.99-1.03)$ & 0.37 \\
\hline
\end{tabular}

Variables included in multivariable model included the variable of interest and variables significant at the $\mathrm{p}<0.05$ level in univariable analysis. ${ }^{*}$ PSA modeled as $\log _{2}$ (PSA). 
**Models also adjusted for the same variables as the obesity model. ADT: androgen-deprivation therapy; BCR: biochemical recurrence; CI: confidence interval; HR: hazard ratio; PSA: prostatespecific antigen; SAI: Subcutaneous adiposity index; VAI: visceral adiposity index

\begin{tabular}{|c|c|c|}
\hline & Multivariable HR (95\% CI) & $\mathbf{p}$ \\
\hline Very low-/Low-risk & $0.80(0.23-2.81)$ & 0.73 \\
\hline Intermediate-risk & $1.11(0.63-1.98)$ & 0.70 \\
\hline High-/Very high-risk & $1.05(0.66-1.68)$ & 0.82 \\
\hline
\end{tabular}

BCR: biochemical recurrence; CI: confidence interval; HR: hazard ratio; NCCN: National Comprehensive Cancer Network.

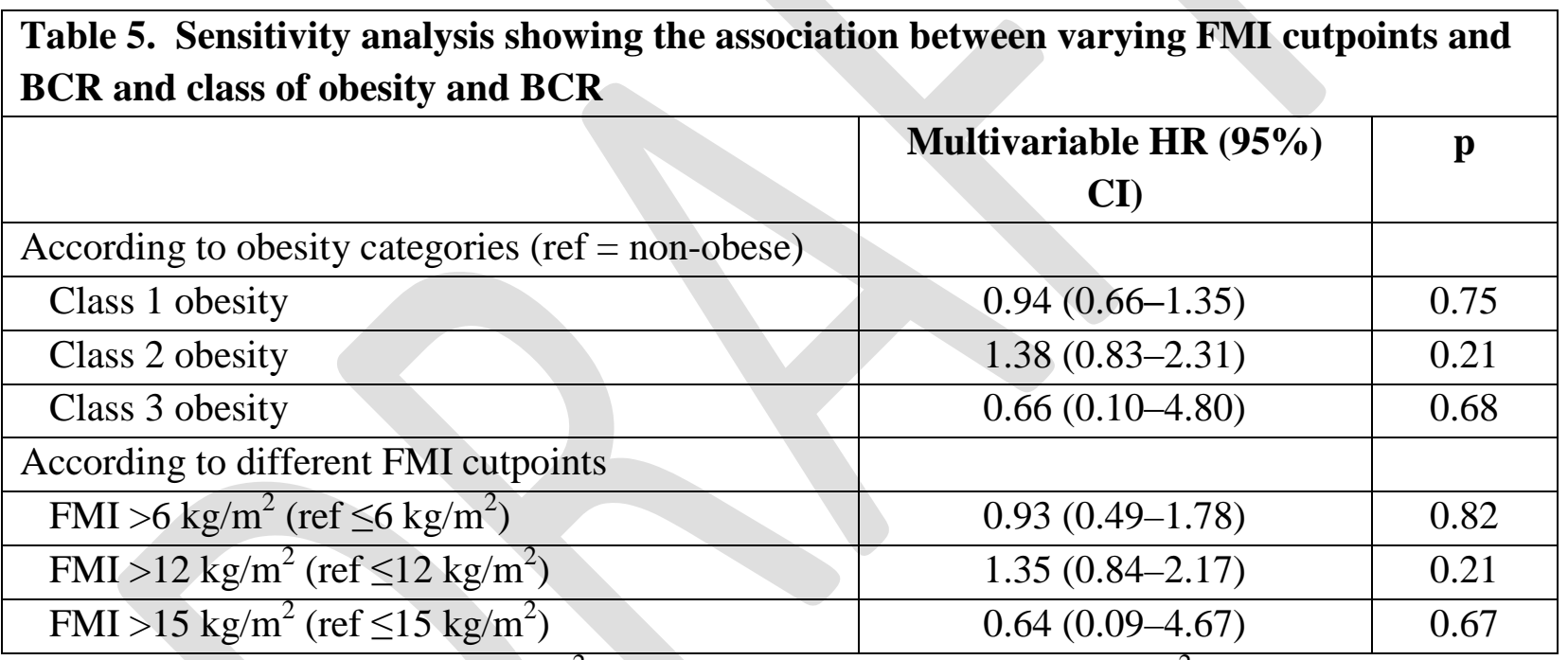

Class 1 obesity $=$ FMI $>9-12 \mathrm{~kg} / \mathrm{m}^{2}$, Class 2 obesity $=$ FMI $>12-15 \mathrm{~kg} / \mathrm{m}^{2}$, Class 3 obesity $=$ FMI $>15$ kg/m². CI: confidence interval; FMI: fat mass index; HR: hazard ratio. 


\begin{tabular}{|c|c|c|c|c|}
\hline \multicolumn{5}{|c|}{$\begin{array}{l}\text { Supplemental Table 1. Cox proportional hazards regression assessing the association of obesity with } \\
\text { systemic progression and overall survival }\end{array}$} \\
\hline & Systemic progression & $\mathbf{p}$ & Overall survival & $\mathbf{p}$ \\
\hline & Multivariable HR (95\% CI) & & Multivariable HR (95\% CI) & \\
\hline Obesity & $0.79(0.46-1.34)$ & 0.38 & $1.06(0.60-1.86)$ & 0.84 \\
\hline Age & & & $1.09(1.04-1.14)$ & $<0.001$ \\
\hline \multicolumn{5}{|l|}{$\begin{array}{l}\text { Pathologic Gleason grade } \\
(\text { ref }=7)\end{array}$} \\
\hline 6 & - & - & $1.42(0.66-3.07)$ & 0.37 \\
\hline $8-10$ & $2.50(1.43-4.38)$ & 0.001 & $1.46(0.72-2.94)$ & 0.28 \\
\hline \multicolumn{5}{|l|}{ pT stage (ref = pT2) } \\
\hline $\mathrm{pT} 3 / 4$ & $2.99(1.60-5.58)$ & $<0.001$ & $1.50(0.75-3.01)$ & 0.26 \\
\hline pN1 disease $(r e f=N 0-x)$ & $2.06(0.82-5.14)$ & 0.12 & $2.47(1.09-5.60)$ & 0.03 \\
\hline Preoperative PSA* & $0.95(0.73-1.23)$ & 0.70 & $y$ & \\
\hline Positive margins & $1.39(0.80-2.42)$ & 0.24 & & \\
\hline Adjuvant ADT & $0.60(0.26-1.38)$ & 0.23 & & \\
\hline
\end{tabular}

Variables included in multivariable model included the variable of interest (obesity) and variables significant at the $\mathrm{p}<0.05$ level in univariable analysis. *PSA modeled as $\log _{2}$ PSA. ADT: androgen-deprivation therapy; CI: confidence interval; HR: hazard ratio; PSA: prostate-specific antigen. 